\section{Effect of presentation modes on paired-associate learning of retardates*}

\author{
PEGGY A. KEILMAN + \\ Louisiana State University in New Orleans, New Orleans, La. 70122
}

Eighteen male retardates were presented individually with a multiple-choice paired-associate task, using one of the following modes of presentation: tutorial or teaching machine. The results clearly indicated that the tutorial mode was superior on the following measures: trials to criterion, number of correct responses during original learning, and absolute retention values after a 1-week interval had elapsed. Further research is needed to determine if the actual presentation procedure or type of feedback is responsible for the differences in these two methods.

Skinner (1954) outlined advantages to be gained from using a teaching machine for instructional purposes which seemed to make this an ideal method for teaching retardates. Recent research (Malpass, 1967, Chap. 9) confirmed this in that several studies have shown that retardates may learn more by programmed instruction than by conventional classroom techniques. Some previous research (Sprague \& Binder, 1962; Price, 1963), however, shows the gains made to be quite modest, even if statistically significant. Neither of these studies gave any evidence of the Ss' mastering the task. Two possible reasons have been suggested for these findings (Green, 1966): one is that merely being correct may not be reinforcing for a retardate, and another is that the students may not be attending to the task. If either of these reasons is correct, many of the advantages to be gained from learning from a teaching machine would be obliterated. Since a study by Malpass, Gilmore, Hardy, \& Williams (1964) had suggested that a tutorial method was just as effective as

*These results were presented at the Southwestern Psychological Association meeting, St. Louis, 1970.

tThe author wishes to express her appreciation to Patricia Malone for supervising the collecting of the data for this experiment. semi- and fully-automated programmed methods, the present investigation compared a tutorial method with a teaching machine method. The $E$ remained in the room with $\mathrm{Ss}$ in the teaching machine group so that potential differences could be attributed to one or the other method, disallowing the possibility of Ss' being inattentive without the E's knowledge. The two groups differed only in the instructional method, which also encompasses a difference in feedback administration, either human or mechanical. Being correct must be a component of each S's reinforcing stimuli if mastery of a given task is to be fully realized.

\section{SUBJECTS}

The Ss were 18 institutionalized male retardates at Magnolia School, a private institution in New Orleans, La. Nine Ss were assigned to each of the experimental groups. The chronological ages and California Achievement Test's (CAT) reading vocabulary total scores of the upper primary and elementary scales were recorded for all Ss.

There were no significant differences between the groups due to age or CAT score. The mean age of each group was 13.67 years, and the standard deviations were 1.46 and 2.19 years for the teaching machine and tutorial group, respectively. The mean CAT score for the machine group was 3.71 , indicating that these Ss were reading in the latter half of the third grade. The standard deviation of this group was .56 school years. The corresponding mean and standard deviation for the tutorial group was 3.56 and .33 .

MATERIALS AND APPARATUS

The stimuli of the eight-item multiple-choice paired-associate list were double-digit numbers $(11,22$, $\ldots, 88)$. The responses were simple nouns (horse, train, apple, table, house, drum, cup, and shoe). Each stimulus term was presented to the $S$ with four response alternatives under it from the set of eight response terms. Four different orders of the learning materials were prepared so that the correct response term could appear in different alternative positions; in addition, the particular alternatives for a given stimulus term varied from order to order. These learning materials were presented to the $\mathrm{Ss}$ in the tutorial group on $5 \times 8$ in. cards and to those in the machine group through the aperture of an MTA Scholar, a teaching machine.

\section{PROCEDURE}

After $S$ was seated, one of the Es showed him the eight stimulus terms and eight response terms and asked him to identify them. If a $S$ failed to identify a word or number, he was asked to repeat the item after being corrected by $\mathrm{E}$. Then standard PA learning instructions were read aloud to the $\mathrm{S}$ which informed him that numbers and words would be paired. All Ss were taught under a confirmation procedure and were instructed to say the stimulus number and then the word that went with it. If correct, the $S$ proceeded to the next item; if incorrect, he had to continue to respond until he got the item correct. Ss were either given 20 trials or continued until they reached a criterion of two errorless trials, whichever came first. The two experimental groups differed only in the following way: the tutorial group had the materials presented to them on $5 \times 8$ in. cards, and $E$ informed the $S$ of the correctness or incorrectness of $h$ is response verbally, while the machine group saw the materials to be learned through the aperture of the MTA Scholar and were told that a lighted $60-\mathrm{W}$ bulb would signify a correct response and the same bulb unlighted would signify an incorrect response.

One week after the original learning session, the Ss were given a recall test which involved seeing the stimulus numbers alone and being asked to write or say the correct response term for each stimulus item. Then a recognition task was given which consisted of the Ss being given a sheet 


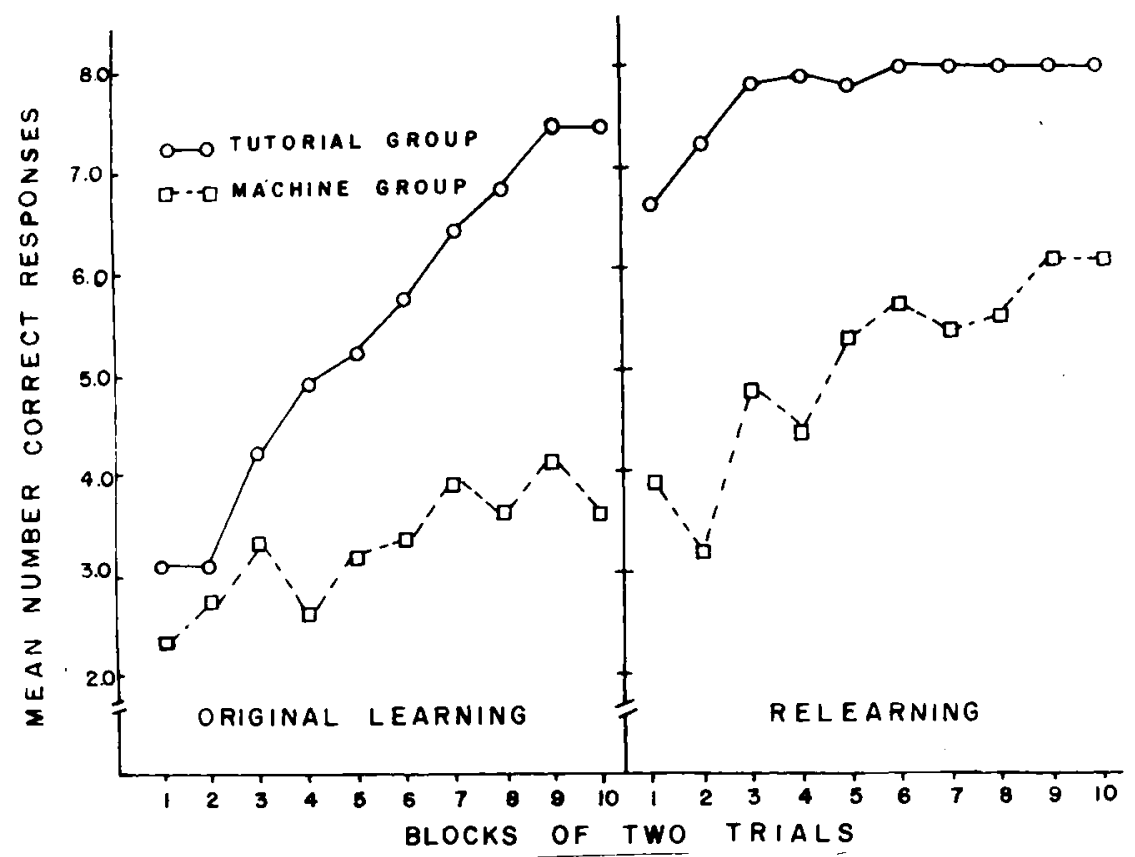

Fig. 1. Mean number of correct responses in blocks of two trials.

containing the stimulus terms with four response alternatives printed under each. They were then asked to circle the correct response term for each stimulus item. Then, following a review of the instructions, each $\mathbf{S}$ was asked to relearn the list to a criterion of two errorless trials or was given 20 trials, whichever came first.

\section{RESULTS}

The mean trials to a criterion for the machine group was 21.22 and this same measure for the tutorial group was 16.44. Eight of the Ss in the machine group and three of the Ss in the tutorial group failed to reach criterion. For computational purposes, these Ss were arbitrarily assigned a score of 22 if they had no errorless trials, or a score of 21 if they had one errorless trial. An analysis of variance was performed on the trials to a criterion during original learning, and significant differences were found with $F(1,16)=5.17, p<.05$.

The mean number of correct responses over the 20 trials was analyzed, using a repeated measures analysis of variance in blocks of two trials. The performance curves across the 10 blocks of two trials for original learning may be seen in Fig. 1. Ss reaching criterion before 20 trials were given perfect scores for the remainder of the trials. The results showed a significant difference between the groups, with $F(1,16)=18.36$, p $<.001$, a significant trial effect, with $F(9,144)=17.01, \quad p<.001$, and $a$ significant interaction effect of Groups by Trials, with $F(9,144)=4.90$, $\mathrm{p}<.01$. An analysis of the simple effect of trials within each group showed that although learning did occur for both groups, it was far superior in the tutorial group. The trial effect produced an $F(9,72)=2.78$, $p<.01$ for the machine group, whereas the tutorial group's $F(9,72)=17.83, p<.001$. The mean number of correct responses out of 16 for the last block of two trials was 7.22 for the machine group and 14.89 for the tutorial group. In other words, almost all of the Ss in the tutorial group were performing at criterion level, while the remaining $S$ s were performing at slightly below the $50 \%$ correct level (25\% correct would be chance).

An analysis of variance on the recall data once again showed the superiority of the tutorial group, with $F(1,16)=16.34, p<.001$. The mean for this group was 3.44 correct responses, while the machine group had a mean of 1.22 . The recognition data also produced significant differences, with $F(1,16)=8.72$, $p<.01$; the number of correct responses on this task was 4.78 for the tutorial group and 2.55 for the machine group. If retention ratios (number retained divided by number correct on the last acquisition trial during original learning) are used to analyze this data, the $F s(1,16)=.03$ and 1.22 for recall and recognition data, respectively, are not significant. The mean retention ratios for the tutorial group were .442 and .631 for recall and recognition data; these same means for the machine group were .425 and .906 .

Data on trials taken to relearn the list after 1 week had elapsed were analyzed and $F(1,16)=29.53$, $\mathrm{p}<.001$. The tutorial group had a mean of 4.78 , while the machine group's mean was 16.33 , which was just slightly less than the mean of 16.44 that the tutorial group had had for original learning. Four of the Ss failed to reach criterion in the machine group during relearning whereas none of the tutorial group failed to do so. DISCUSSION

The results indicate that the tutorial method was a more effective mode of presentation than the teaching machine for teaching retardates the multiple-choice paired-associate task. This method, of course, has little of the expedience of the conventional classroom or teaching machine procedure. The very favorable results with the tutorial method, however, reduce some of this differential expedience effect due to the Ss' reaching criterion, in some cases, in one session or, at most, two sessions, whereby the Ss in the machine group needed two or more sessions to learn. A previous study (Malpass et al, 1964) used a 1:4 supervisor-pupil ratio with machine instruction, indicating that this method is not as expedient as might be expected, particularly if the students learn more slowly.

Further research is necessary to determine which aspect inherent in these two instructional modes is responsible for the results. The two groups differed not only in the way the task materials were presented, but also in the way feedback was administered. A teaching machine that used either a taped voice or a pictorial display for feedback might be more effective than one using a light. The Es reported that the $S s$ in the machine group were more restless and occasionally attempted to interact with the machine, indicating that this feedback condition is ineffective with this group.

\section{REFERENCES}

GREENE, F. M. Programmed instruction techniques for the mentally retarded. In N. E. Enis (Ed.), International review of reseorch in mental retardation. New York: Academic Press, 1966. Pp. 209-239.

MALPASS, L. F. Programmed instruction for retarded children. In A. A. Baumeister (Ed.), Mental retardation. Chicago: Aldine, 1967. Pp. 212-231.

M ALPASS, L. F., HARDY, M. W., GILMORE, A. S. \& WILLIAMS, C. F. Automated instruction for retarded children. American Journal of Mental Deficiency, 1964, 69, 405-412.

PRICE, J. E. Automated teaching programs with mentally retarded students. American Journal of Mental Deficiency, 1963, 68, 69-72.

SKINNER, B. F. The science of learning and the art of teaching. Harvard Educational Review, 1954, 24, 86-97.

SPRAGUE, R. L., \& BINDER, A. Automated arithmetic instruction for the retarded. Progress report, PHS Grant M-5647(A), 1962. 